\title{
Targeted temperature management and cardiac arrest after the TTM-2 study
}

\author{
Fabio Silvio Taccone ${ }^{1 *}$, Jean-Baptiste Lascarrou ${ }^{2}$ and Markus B. Skrifvars ${ }^{3}$
}

Keywords: Temperature, Cardiac arrest, Randomized trials, Outcome

\section{Background}

The use of targeted temperature management (TTM) has been recommended for two decades in the management of patients after cardiac arrest; however, the quality of evidence behind this recommendation is moderate to low and refers only to out-of-hospital cardiac arrest (OHCA) [1-4]. Recently, Dankiewicz et al. (TTM-2 study) reported that TTM at $33^{\circ} \mathrm{C}$ did not lower the incidence of death or 6-month poor neurological outcome than targeted normothermia in 1900 unconscious OHCA patients [5], with more arrhythmias resulting in hemodynamic compromise observed in the $33{ }^{\circ} \mathrm{C}$ group. There was no benefit of hypothermia in any of the prespecified sub-groups, including age, initial rhythm or duration of resuscitation. It is likely that these recent data will affect the use of TTM in clinical practice.

\section{TTM in cardiac arrest}

How can we interpret the TTM-2 findings? The first conclusion could be the lack of benefits of TTM after cardiac arrest. Indeed, the TTM-2 study had the largest cohort of patients so far and was conducted using the best statistical methodology [5], while previous studies [1, 2] had many methodological biases (i.e., no power calculation, limited cohorts, early stopping, no blinded assessors of primary outcome, no prognostication guidelines). Also, as the general management of patients after cardiac arrest has improved over time (i.e., early recognition and

*Correspondence: ftaccone@ulb.ac.be

1 Department of Intensive Care, Erasme Hospital, Université Libre de Bruxelles (ULB), Route de Lennik, 808, 1070 Brussels, Belgium

Full list of author information is available at the end of the article treatment of the cause, hemodynamic and ventilatory management, organ support) [3], TTM might add only minimal benefits. Moreover, the experimental literature supporting the effectiveness of TTM may not be easily translated in humans, with a lack of clinically relevant long-term neurological outcomes and of reproducibility in all species [6].

A second interpretation could be that all the randomized studies on TTM after cardiac arrest are not entirely comparable (Table 1 ); the TTM-2 study findings would be applicable in the setting of OHCA of cardiac causes, with frequent use of bystander CPR (i.e., short no-flow time and less severe initial anoxic injury), a high proportion of patients with acute myocardial infarction and a low occurrence of shock on admission. On the contrary, in patients with an initial non-shockable rhythm due to respiratory/hypoxic causes and hemodynamic instability, the use of hypothermia at $33^{\circ} \mathrm{C}$ could be considered more effective than normothermia, in particular for in-hospital cardiac arrest [4]. Secondary analyses of the TTM-2 study and individual patient meta-analyses from available datasets of randomized trials may identify some subgroups of patients who are better candidates for TTM and should be considered for future research.

A third interpretation could be the limited applicability in common practice. The TTM-2 study had high patients' heterogeneity (i.e., shockable and non-shockable rhythms; no age limit), a very short no-flow time and a large number of bystander-initiated resuscitation (implying a limited brain injury), which are not common characteristics of CA patients in many registries. Nonetheless, the TTM-2 study included patients in a higher number of countries and several continents when compared to other original author(s) and the source, provide a link to the Creative Commons licence, and indicate if changes were made. The images or other third party material in this article are included in the article's Creative Commons licence, unless indicated otherwise in a credit line to the material. If material is not included in the article's Creative Commons licence and your intended use is not permitted by statutory regulation or exceeds the permitted use, you will need to obtain permission directly from the copyright holder. To view a copy of this licence, visit http://creativecommons.org/licenses/by/4.0/. The Creative Commons Public Domain Dedication waiver (http://creativecommons.org/publicdomain/zero/1.0/) applies to the data made available in this article, unless otherwise stated in a credit line to the data. 
Table 1 Characteristics of the clinical randomized clinical studies comparing hypothermia at $33^{\circ} \mathrm{C}$ with standard of care (i.e., no temperature control or normothermia) or $36{ }^{\circ} \mathrm{C}$ targets. For continuous variables, data are presented as mean $\pm \mathrm{SD}$ or median (IQRs), as available in the main manuscript

\begin{tabular}{|c|c|c|c|c|c|}
\hline & Dankiewicz et al. [5] & HACA group [2] & Bernard et al. [1] & Nielsen et al. [7] & Lascarrou et al. [4] \\
\hline Design & Multicentric & Multicentric & Single-Centre & Multicentric & Multicentric \\
\hline N (HT group) & $1861(930)$ & $275(138)^{*}$ & $79(43)^{* *}$ & 939 (473) & $584(284)$ \\
\hline Age, years & $64 \pm 13$ & $59(49-67)$ & $67(49-89)$ & $64 \pm 12$ & $67(57-76)$ \\
\hline Male gender & $80 \%$ & $77 \%$ & $58 \%$ & $83 \%$ & $65 \%$ \\
\hline $\mathrm{OHCA}$ & $100 \%$ & $100 \%$ & $100 \%$ & $100 \%$ & $74 \%$ \\
\hline Bystander CPR & $82 \%$ & $49 \%$ & $49 \%$ & $73 \%$ & $70 \%$ \\
\hline Shockable rhythm & $72 \%$ & $96 \%$ & $100 \%$ & $79 \%$ & $0 \%$ \\
\hline Time to ROSC, $\mathrm{min}$ & $25(16-40)$ & $22(17-33)^{*}$ & $27 \pm 13$ & $25(18-40)$ & $18(10-25)$ \\
\hline Cause of Arrest & Cardiac/UNK & Cardiac & Cardiac & Cardiac/UNK & All** \\
\hline Shock on Admission & $28 \%$ & $49^{*}$ & NR & $15 \%$ & $56 \%$ \\
\hline STEMI on Admission & $41 \%$ & NR & NR & $40 \%$ & $16 \%$ \\
\hline Lactate, $\mathrm{mmol} / \mathrm{L}$ & $5.9 \pm 4.4$ & NR & $8.3(2.2-14.9)$ & $6.7 \pm 4.5$ & $5.8(3.2-9.0)$ \\
\hline Outcome Assessment & 6 months & 6 months & Hospital Discharge & 6 months & 3 months \\
\hline Mortality, \%* & $50 \%$ & $41 \%$ & $51 \%$ & $50 \%$ & $81 \%$ \\
\hline UO Assessment Scale & mRS 4-6 & CPC $3-5$ & CPC $3-5$ & CPC $3-5$ & CPC 3-5 \\
\hline UO, \% & 55 & 45 & 51 & 54 & 90 \\
\hline Prognostication Rules & Present & Absent & Absent & Present & Present \\
\hline Generalisability/Bias & High/low & Low/high & Low/high & High/low & High/moderate \\
\hline
\end{tabular}

HACA, Hypothermia After Cardiac Arrest; N, total number of included patients; HT, hypothermia; OHCA, out-of-hospital cardiac arrest; CPR, cardiopulmonary resuscitation; ROSC, return of spontaneous circulation; min, minutes, UNK, unknown; STEMI; ST-elevation myocardial infarction; UO, unfavorable neurological outcome; mRS, modified Rankin scale; CPC, Cerebral Performance Category

*In the hypothermia group

**Mainly respiratory causes

studies [1, 4] (i.e., high generalisability); also, time to resuscitation, time to target temperature and rewarming rate were comparable to previous trials $[2,4]$ (i.e., TTM was provided similarly than in studies reporting benefits from hypothermia); the less strict inclusion criteria (i.e., including some unwitnessed cardiac arrest or non-shockable rhythm as well as elderly patients, i.e., $>75$ years of age) than other studies $[2,4]$ allowed a larger proportion of eligible patient to be enrolled (i.e., reduced selection bias); the presence of strict prognostication rules minimized the risks of limitations of life-sustaining therapies decided by unblinded investigators $[1,2]$ (i.e., reduced performance bias).

A fourth interpretation could be the large inclusion of patients with extreme patterns of brain injury, in whom TTM would provide only minimal benefits. The TTM-2 study required randomization within $3 \mathrm{~h}$ from return of spontaneous circulation (ROSC) to avoid late application of hypothermia, so that patients with mild brain damage were also included. Also, patients with irreversible brain injury and no chance of recovery regardless of different therapeutic interventions might also be enrolled. Future studies are needed to identify prognostic tools able to quantify earlier the severity of hypoxic brain injury and to identify those patients in whom neuroprotective strategies, including TTM, should be evaluated.

How should we use then TTM after cardiac arrest? Clinicians should consider that the "normothermic" arm (i.e., aiming for a temperature below $37.8{ }^{\circ} \mathrm{C}$ ) in the TTM-2 study required use of sedation for $40 \mathrm{~h}$ in all patients and active temperature management (i.e., cooling devices with temperature-feedback control; relatively slow rewarming and avoidance of fever for $72 \mathrm{~h}$ ) in almost $50 \%$ of them. As such, abandoning any temperature control protocol in cardiac arrest patients is not acceptable. After the publication of the TTM study in 2013 [7], observational studies have already indicated that changes temperature targets to $36{ }^{\circ} \mathrm{C}$ were associated with a less accurate TTM delivery and worse outcomes when compared to $33{ }^{\circ} \mathrm{C}$ target [8]. Temperature control after CA remains a complex and time-consuming intervention, which, if inadequately applied (i.e., no sedation, no active temperature and fever control) might result in unpredictable temperature trajectories and in a less precise patients' management, with deleterious effects on neurological outcome. Interestingly, none of these randomized studies could provide a "high quality" TTM [9], because of human and technical constraints 
which could alter speed of cooling, reduce the accuracy of temperature control, shorten the rewarming period or expose patients to prolonged post-TTM fever. Although high-quality TTM was not an independent predictor of favorable neurological outcome in a recent study [10], additional research is required to understand how highquality TTM could influence the results observed in large randomized trials.

\section{Conclusions}

Physicians treating patients resuscitated after OHCA should consider that active maintenance of normothermia (i.e., specific protocol for sedation, prognostication and active temperature control) appears to be the optimal strategy for cardiac arrest of cardiac origin and with early resuscitation. Whether TTM at $33^{\circ} \mathrm{C}$ still could be indicated in non-shockable rhythms due to non-cardiac causes remains to be considered. Future studies in inhospital cardiac arrest are warranted. Abandoning TTM completely is not an option.

\section{Abbreviations}

CPR: Cardiopulmonary resuscitation; ICU: Intensive Care Unit; OHCA: Out-ofhospital cardiac arrest; ROSC: Return of spontaneous circulation; TTM: Targeted temperature management.

\section{Acknowledgements}

None.

\section{Authors' contributions}

FST, JBL and MBS drafted the present manuscript. All authors read and approved the final manuscript.

\section{Funding}

No funding was provided for this study.

Availability of data and materials

Not applicable.

\section{Declarations}

Ethics approval and consent to participate

Not applicable.

\section{Consent for publication}

Not applicable.

\section{Competing interests}

FST and JBL received speaker fees from BD and ZOLL. MBS received speakers fees and travel grants from BARD Medical (Ireland).

\section{Author details}

${ }^{1}$ Department of Intensive Care, Erasme Hospital, Université Libre de Bruxelles (ULB), Route de Lennik, 808, 1070 Brussels, Belgium. ${ }^{2}$ Service de Médecine Intensive Réanimation, Centre Hospitalier Universitaire, Nantes, France. ${ }^{3}$ Department of Emergency Care and Services, Helsinki University Hospital and University of Helsinki, Helsinki, Finland.

Received: 26 July 2021 Accepted: 29 July 2021

Published online: 04 August 2021

\section{References}

1. Bernard SA, Gray TW, Buist MD, Jones BM, Silvester W, Gutteridge G, et al. Treatment of comatose survivors of out-of-hospital cardiac arrest with induced hypothermia. N Engl J Med. 2002;346:557-63.

2. Hypothermia after Cardiac Arrest Study Group. Mild therapeutic hypothermia to improve the neurologic outcome after cardiac arrest. N Engl J Med. 2002;346:549-56.

3. Nolan JP, Sandroni C, Böttiger BW, Cariou A, Cronberg T, Friberg H, et al. European Resuscitation Council and European Society of Intensive Care Medicine guidelines 2021: post-resuscitation care. Intensive Care Med. 2021;47(4):369-421.

4. Lascarrou JB, Merdji H, Le Gouge A, Colin G, Grillet G, Girardie P, et al. Targeted temperature management for cardiac arrest with nonshockable rhythm. N Engl J Med. 2019;381(24):2327-37.

5. Dankiewicz J, Cronberg T, Lilja G, Jakobsen JC, Levin H, Ullén S, et al. Hypothermia versus normothermia after out-of-hospital cardiac arrest. N Engl J Med. 2021;384(24):2283-94.

6. Olai $H$, Thornéus $G$, Watson $H$, Macleod M, Rhodes J, Friberg $H$, et al. Meta-analysis of targeted temperature management in animal models of cardiac arrest. Intensive Care Med Exp. 2020;8(1):3.

7. Nielsen N, Wetterslev J, Cronberg T, Erlinge D, Gasche Y, Hassager C, et al. Targeted temperature management at 33 degrees $C$ versus 36 degrees $C$ after cardiac arrest. N Engl J Med. 2013;369:2197-206.

8. Minini A, Annoni F, Peluso L, Bogossian EG, Creteur J, Taccone FS. Which target temperature for post-anoxic brain injury? A systematic review from "real life" studies. Brain Sci. 2021;11(2):186.

9. Taccone FS, Picetti E, Vincent JL. High quality targeted temperature management (TTM) after cardiac arrest. Crit Care. 2020;24(1):6.

10. De Fazio C, Skrifvars MB, Søreide E, Grejs AM, Di Bernardini E, Jeppesen AN, et al. Quality of targeted temperature management and outcome of out-of-hospital cardiac arrest patients: a post hoc analysis of the TTH48 study. Resuscitation. 2021;21(165):85-92.

\section{Publisher's Note}

Springer Nature remains neutral with regard to jurisdictional claims in published maps and institutional affiliations.

\footnotetext{
Ready to submit your research? Choose BMC and benefit from:

- fast, convenient online submission

- thorough peer review by experienced researchers in your field

- rapid publication on acceptance

- support for research data, including large and complex data types

- gold Open Access which fosters wider collaboration and increased citations

- maximum visibility for your research: over 100M website views per year
}

At BMC, research is always in progress.

Learn more biomedcentral.com/submissions 